\title{
Article \\ Unique Hair Properties that Emerge from Combinations of Multiple Races
}

\author{
Toshie Takahashi \\ R\&D—Development Research, Kao Corporation, 2-1-3, Bunka, Sumida-ku, Tokyo 131-8501, Japan; \\ takahashi.toshie@kao.com; Tel.: +81-3-5630-9972
}

Received: 13 May 2019; Accepted: 19 June 2019; Published: 21 June 2019

\begin{abstract}
The fusion of ethnicity in human populations is becoming increasingly common, so the conventional definition of ethnicity is going to become deficient. The aim of this study was to investigate the hair properties which emerge from combinations of multiple races. Hair fibers collected from mixed-race subjects were investigated and classifications of hair shape as well as measurements of thickness, ellipticity and surface damage were carried out. The results show that hair shapes varied widely: straight hair and very curly hair often existed together on the heads of individuals with mixed ethnicity. Curly hair tended to be thicker than loose wavy hair. As for damage to the hair surface, the hairs of mixed-race subjects showed a very unique property in that they were much more severely damaged near the root (the proximal end) than the hairs of monoracial subjects. The hair shape (curly or loose wavy) was not related to the level of damage. The severe damage near the proximal end is thought to be caused by entanglement, due to the presence of various curl phases. This study reports the unique characteristics of hairs of subjects with mixed ethnicity, which have never been noted in the previous studies on subjects with a monoracial background.
\end{abstract}

Keywords: hair; ethnicity; mixed; hair damage; hair shape

\section{Introduction}

Differences in hair properties depending on ethnicity have been widely studied [1-12]. These studies have revealed the unique hair properties (such as shape, curliness, color, follicle, mechanical behavior, damage mechanism, etc.) for each race. In most cases, ethnicity has been classified into three groups: African, Asian and Caucasian. It has been reported that Asian hair is generally straight and is the thickest, while its cross-section is the most round-shaped among these three. Caucasian hair is generally straight or wavy and is the thinnest, while its cross-section is relatively elliptic. As for African hair, it is very curly, its thickness is intermediate and the shape of cross-section is highly elliptic. Difference in damage caused through daily grooming has also been found: Asian hair cuticles tend to split at the cell membrane complex between the cuticle cells, and then the cuticle cell lifts up. On the other hand, Caucasian hair cuticles tend to be damaged inside the cuticle cell, so the endocuticle, the most fragile substructure of the cuticle cell, is exposed.

However, the fusion of ethnicities is becoming increasingly common throughout the world, so that these definitions mentioned above are going to be deficient. Studies of the hair of subjects with a mixed racial background have not been reported so far, probably because the histories of individuals with mixed ethnicities are too diversified to develop unified properties.

The ethnic composition of Brazil in 2010 was announced by the Instituto Brasileiro de Geografia e Estatística that the ratio of subjects with mixed ethnic backgrounds represents nearly one-half $(43 \%)$, so understanding the properties of the hair of mixed-race subjects would be beneficial to improve Brazilian hair-care products. 
The goal of this study is to clarify the hair properties which emerge from combinations of multiple races, not to identify racial characteristics.

\section{Materials and Methods}

\subsection{Hair Samples}

Mixed-race subjects: Hair fibers that had fallen out after shampooing were collected from 9 women ranging from 19 to 41 years of age, who were born and grew up in Brazil. They declared their own ethnic backgrounds. All the subjects had 2 or more backgrounds: at least 6 subjects were from African and Caucasian backgrounds (other ethnicities, such as Asian and Native Indian, were also involved in some cases). Three subjects did not have detailed information. Fifty or more hair fibers were obtained from each subject.

Monoracial subjects: For comparison, hair fibers that had fallen out after shampooing were also collected from 2 Caucasian women, 10 African women, and 1 Japanese woman, who were residing in Brazil, US and Japan, respectively. In addition hair fibers were cut very close to the scalp of Asian (9 Chinese and 11 Japanese) and 8 Caucasian women, who were residing in China, Japan and Germany, respectively.

In the case of the Caucasian and Asian subjects, none of the subjects had any chemical treatment in the past 6 months at the time of sampling. All experiments were carried out on hairs using the range of $60 \mathrm{~mm}$ from the proximal end, in order to eliminate the effect of chemical treatments and longtime weathering stress. Seven of the African subjects, however, had some chemical treatments in the past 6 months, so only the parts near the scalp, which seemed to be less damaged, were used. This study was approved by the Ethical Review Board of the Kao Corporation and the subjects received detailed information prior to providing their hair samples. After collection, hair fibers were immersed in an aqueous sodium polyoxyethylene lauryl ether sulphate solution (15\%), adjusted to $\mathrm{pH} 7$ with phosphoric acid, at $40^{\circ} \mathrm{C}$ for $3 \mathrm{~min}$. The samples were then rinsed by immersion in deionized water at $40^{\circ} \mathrm{C}$ for $3 \mathrm{~min}$. This rinsing process was repeated and then the samples were air-dried. All these processes were carried out very carefully not to entangle the hair fibers.

\subsection{Classification of Hair Shape}

A new classification method of hair shape was suggested by L'Oréal researchers in 2007 [13] that classifies hair shapes into 8 types based on just curliness and waviness, but not on ethnicity. In this study, the classification of hair shape was performed using that methodology. From the hair fibers of 9 mixed, 10 Caucasian, 10 African and 10 Asian (5 Chinese and 5 Japanese) subjects, twenty hair fibers that seemed to have an almost average thickness for that individual subject were selected and classified according to their shape.

\subsection{Thickness and Ellipticity}

The thickness of each hair sample was measured using a laser scan micrometer (LSM-6200; Mitsutoyo Corp., Kanagawa, Japan) at $20{ }^{\circ} \mathrm{C}$ and $40 \%$ relative humidity. Measurements were made at the points of 25, 30 and $35 \mathrm{~mm}$ from the proximal end. At each of those points, the hair sample was rotated one turn and was measured every 30 degrees from 0 to 150 degrees. Consequently, 18 values were obtained for each hair fiber and were then averaged as the thickness.

Next, each hair fiber was rotated one complete turn. The maximum and minimum thickness values ( $T_{\max }$ and $T_{\min }$, respectively) at each point $(25,30$ and $35 \mathrm{~mm}$ from the proximal end) were recorded. The values of $T_{\min } / T_{\max }$ were calculated and were averaged as the ellipticity.

\subsection{Evaluation of Hair Damage}

The following 2 types of hair damage were evaluated (Figure 1). 
- $\quad$ Lifted cuticle

- $\quad$ Exposed endocuticle

The points at 10, 20, 30, 40 and $50 \mathrm{~mm}$ from the proximal end of the hair were photographed with a profile microscope (VK-9500; Keyence, Osaka, Japan). Levels of damage types were measured as the ratios of the area which showed the respective damage, using an image analyzing software Image-Pro®Plus Version 6.1 (Media Cybernetics, MD, USA), following a previously described method [14].

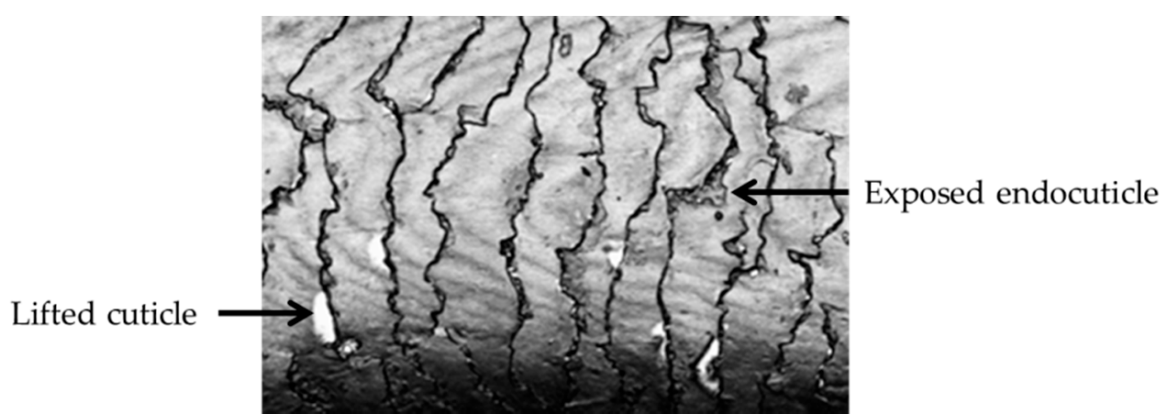

Figure 1. Image of damaged hair surface obtained with a profile microscope. Lifted cuticle, which is observed as white area, is caused by the splitting of the cell membrane complex between cuticle cells. Exposed endocuticle, which is seen as gray rough area, is caused by breakage of cuticle cell.

\subsection{Statistical Analysis}

Statistical significance was determined by t-test, using Excel 2010 (Microsoft, Redmond, WA, USA).

\section{Results}

\subsection{Shape (Curliness)}

Hair samples were classified into eight types (Figure 2). As the number increases, the waviness (or curliness) becomes tighter, for example type I is almost straight, type IV is curly and type VIII is very tight curly hair [13].

The hair shapes of the mixed-race subjects varied widely, it was noticed that straight hair and very curly hair often existed together on the heads of individuals. Four of the eight types of hair, from I (straight) to IV (curly), were seen together on four subjects (M1, M2, M3 and M4), and five types, from I (straight) to V (curly), were seen together on two subjects (M8 and M9). In comparison, the hair shapes of the subjects with single ethnicity were distributed in a narrow range: On eight Caucasian subjects, three types (from I to III or from II to IV) were seen. On the other two subjects, four types, from I to IV, were seen. African hairs were distributed in one or two types and type VIII was mostly the major one. As for Asian subjects, only the type I and II were mostly observed (Figure 2).

These diversely distributed hair shapes of the mixed-race subjects may lead to some variations in hair properties. Five mixed subjects who had four or five types of hair shapes were selected (M1, M2, M4, M8 and M9 in Figure 2). Hair fibers of types I or II and types IV or V (hereafter the former will be referred to as loose wavy hair, the latter will be referred to as curly hair) were collected from each subject, and then their thickness, ellipticity and damage were evaluated. 

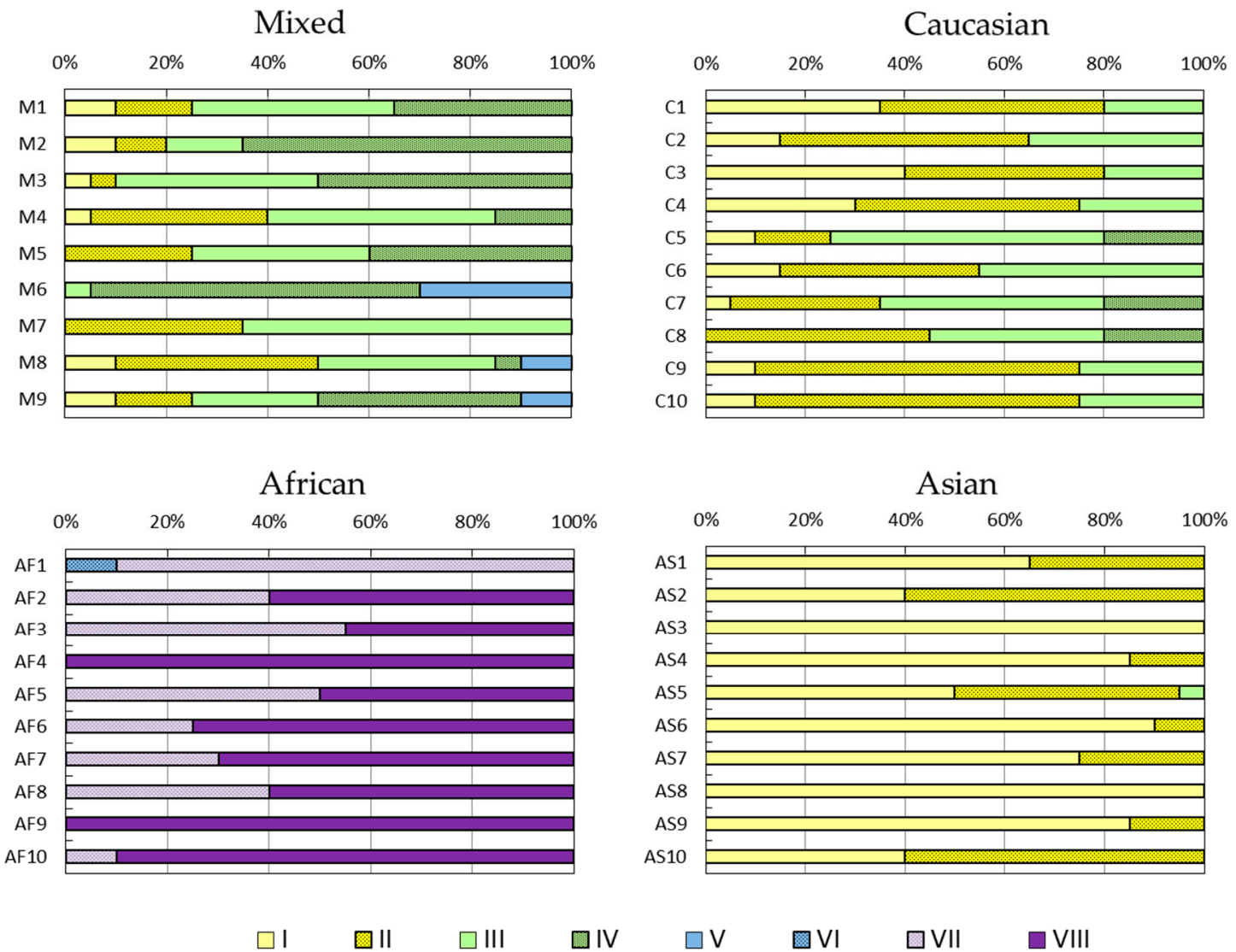

Figure 2. Classification of mixed, Caucasian, African and Asian hairs.

\subsection{Thickness and Ellipticity}

Ten loose wavy hair fibers and 10 curly hair fibers were collected from each mixed-race subject, and were analyzed for thickness and ellipticity (Figure 3). In all of these cases, the curly hair fibers were thicker and more elliptical than the loose wavy hair fibers, and there were statistically significant differences between loose wavy and curly hairs $(p<0.01)$.

a

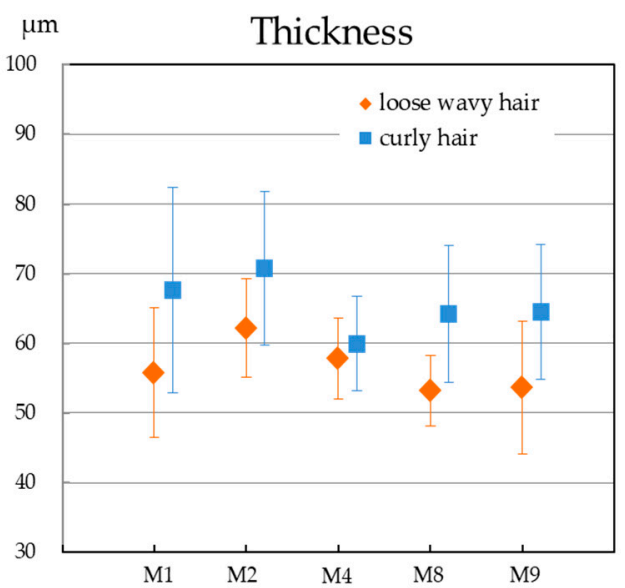

$\mathrm{b}$

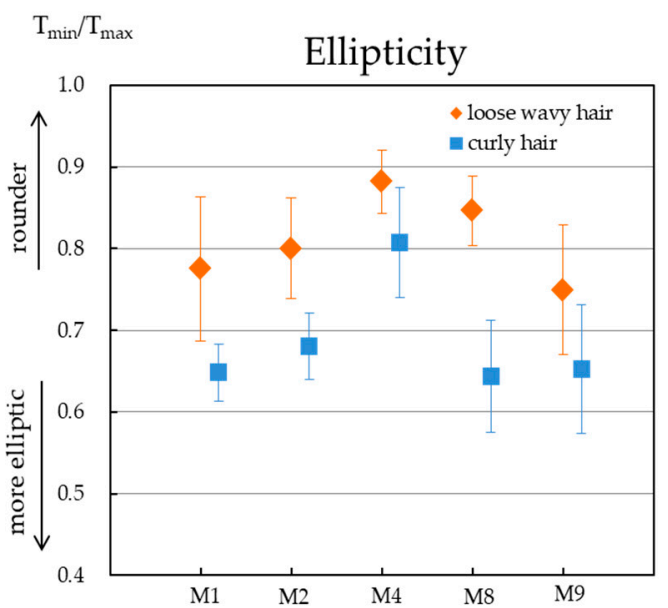

Figure 3. Thickness and ellipticity of mixed hairs. (a) Thickness; (b) ellipticity. In all cases there were statistically significant differences between loose wavy and curly hairs $(p<0.01)$. 


\subsection{Damage}

Damage of the hair surface of the mixed-race subjects was investigated in terms of the following two types of damage (Figure 1).

- Lifted cuticle

- Exposed endocuticle

Six loose wavy hairs and six curly hairs were taken from each mixed-race subject. For comparison, two hair fibers cut close to the scalp from each Japanese, Chinese and Caucasian subject were evaluated in the same manner. The numbers of the hair samples were 22, 18 and 16, respectively. All of them were classified as loose wavy hair.

The results were analyzed regarding the following points:

- $\quad$ Loose wavy hair vs. curly hair of each subject

- $\quad$ vs. Monoracial subjects

\subsubsection{Lifted Cuticle}

The results of the mixed-race subjects are shown in Figure 4a, while the results of the monoracial subjects are shown in Figure $4 \mathrm{~b}$. There were no statistically significant differences between loose wavy and curly hairs of the mixed-race subjects $(p>0.09)$ (Figure 4a). The level of lifted cuticles was kept at a constant level in this range (60 $\mathrm{mm}$ from the root). In contrast, the level of the lifted cuticle of Asians increased from the proximal end to the distal end in this range, while it was similar to that of the mixed-race subjects at near the root (Figure $4 b$ ). In Figure 4, the + indicates that there are statistically significant differences between the marked data and the data at $10 \mathrm{~mm}(p<0.05)$. It was found that damage increased especially on Chinese hair, from $30 \mathrm{~mm}$ onward.

a

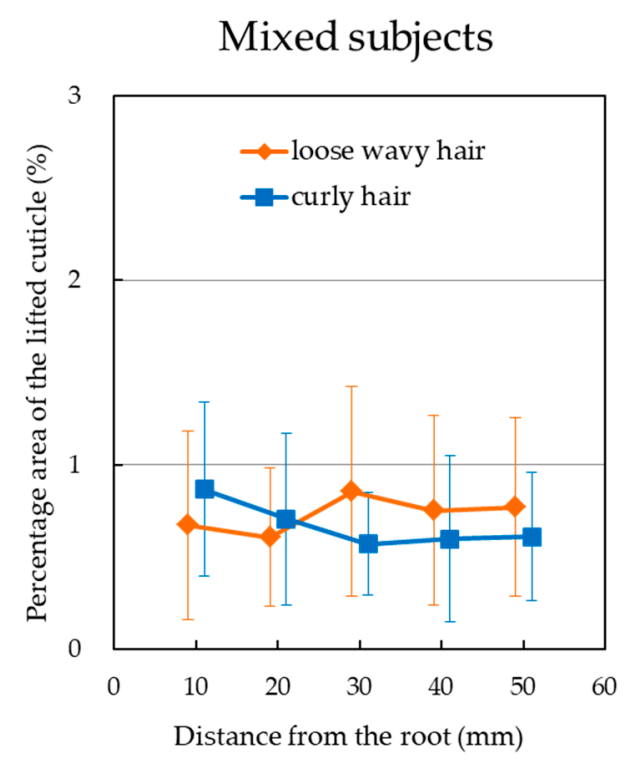

b

Asian and Caucasian

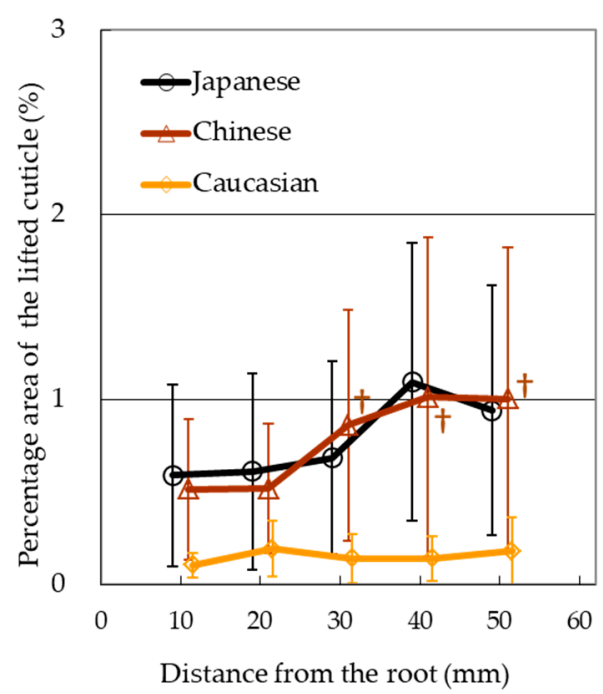

Figure 4. (a) The levels of "lifted cuticle" damage of the mixed-race subjects are plotted according to hair shape. There were no statistically significant differences between loose wavy and curly hairs $(p>0.09)$. (b) The levels of "lifted cuticle" damage of the monoracial subjects. The + indicates statistically significant differences between the marked data and the data at $10 \mathrm{~mm}(p<0.05)$.

\subsubsection{Exposed Endocuticle}

Figure 5 a shows the results of the mixed-race subjects, and Figure $5 b$ shows the results of Asians and Caucasians. The results show that: 
- The level of damage of mixed-race subjects seems unrelated to the hair shape. There were no statistically significant differences between loose wavy and curly hairs $(p>0.05)$ (Figure 5a).

- Throughout this range, the level of damage was much higher in mixed-race subjects than in monoracial subjects.

- Near the proximal end, this type of damage was clearly observed in the mixed-race subjects, while it was hardly seen in monoracial subjects.

- Damage of the hair of mixed-race subjects was already at a high level near the proximal end and kept at a constant level towards the distal end, differently from those of Chinese and Caucasian hair. In Figure 5, the $\dagger$ and $\ddagger$ indicate statistically significant differences between the marked data and the data at $10 \mathrm{~mm}(p<0.05$ and $p<0.01$, respectively). While the case at $40 \mathrm{~mm}$ of the curly hairs was exceptional, however, in all other cases of mixed-race subjects, no damage-increasing tendency was seen. In contrast, damage increased on Chinese and Caucasian hair, from 40 and $30 \mathrm{~mm}$ onward, respectively.

a

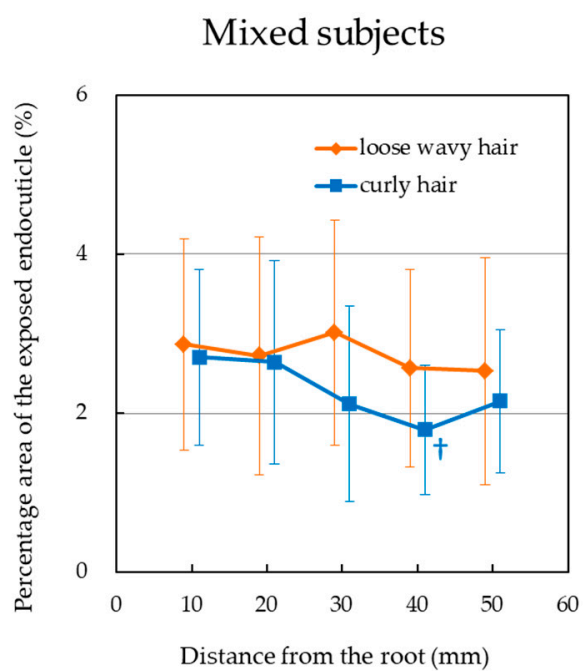

b

Asian and Caucasian

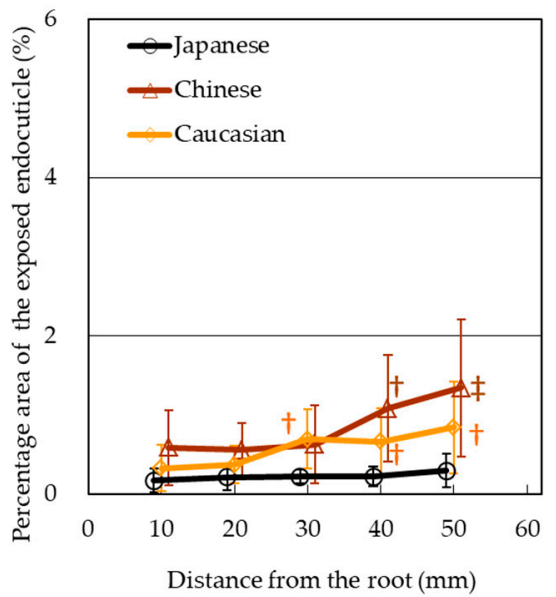

Figure 5. (a) The levels of "exposed endocuticle" damage of the mixed-race subjects are plotted according to hair shape. There were no statistically significant differences between loose wavy and curly hairs $(p>0.05)$. (b) The levels of "exposed endocuticle" damage of the monoracial subjects. The $†$ and $\ddagger$ indicate statistically significant differences between the marked data and the data at $10 \mathrm{~mm}$ $(p<0.05$ and $p<0.01$, respectively).

\section{Discussion}

The fusion of ethnicities in human populations is becoming increasingly common, so the conventional definitions of ethnicities are going to become deficient. This study reports the unique characteristics of hairs which emerge from combinations of multiple races. Definition of any racial characteristics is not intended here.

\subsection{Damage Properties}

The 2 types of hair damage of mixed-race subjects were found to have the following features in common:

- The shape of hair fibers (loose wavy or curly) is not related to the damage level.

- Damage is clearly severe near the proximal end.

Lifted cuticle is caused by the splitting of the cell membrane complex between cuticle cells. Exposed endocuticle is caused by breakage of cuticle cells. It was reported that the latter type of damage is 
enhanced by inherent fragility of cuticular component (endocuticle) and friction stimulus [1,2]. In the case of hair of mixed-race subjects, the level of the exposed endocuticle was high at the root but it keeps the level within the range of $60 \mathrm{~mm}$ from the proximal end. This means that the hair structure is not congenitally fragile. Similarly, the possibility that friction stimulus accumulated during daily grooming is the cause of the damage should be ruled out. It seems that mixed hair receives some major stress near the scalp, but as the hair grows, it is kept away from that.

Thus, the following hypothesis is proposed: Entanglement due to the simultaneous presence of various types of hairs.

Due to the wide variety of hair shapes in each individual, the hair fibers cannot be aligned and are therefore quite easily entangled (Figure 6). Furthermore, hair fibers are most dense at the scalp and it was found that Brazilians customarily shampoo their scalp by rubbing it tightly in order to keep it clean [15]. Consequently, near the proximal end, each hair receives especially severe frictional stress and then cuticles are drastically chipped. No matter whether the shape is loose wavy or curly, hair fibers are involved and entangled with each other, and so are similarly damaged.

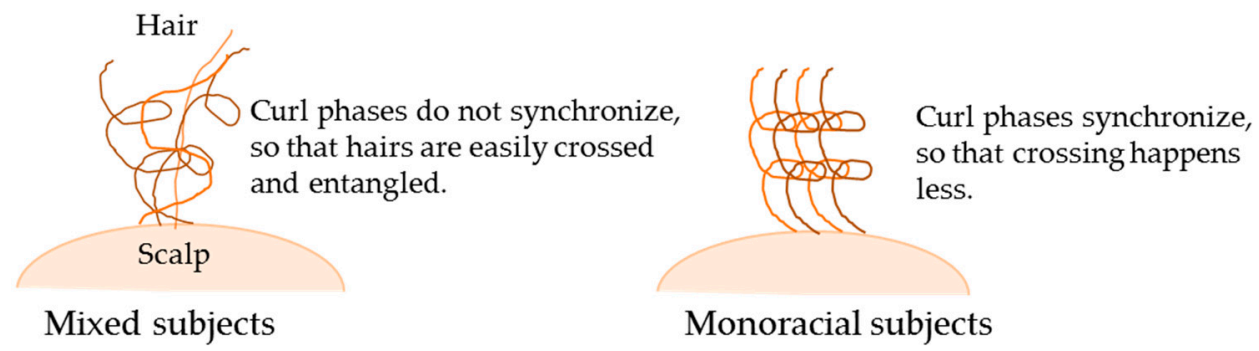

Figure 6. Image of the entanglement of hairs near the scalp.

It is thought that the wide variation of hair shapes, a unique feature of subjects with mixed ethnicity, leads to the severe breakage of the cuticles near the scalp.

It was reported that Brazilian women tend to use large amounts of hair-conditioning products, such as creams, oils, butters, etc., which are effective in reducing stress during the grooming process [16]. This custom, unique to Brazilians, may suppress the entanglement of the hair and might be the reason why the hair damage of the mixed-race subjects does not proceed towards the distal end.

\subsection{Curly Hairs}

A previous study on subjects of African descent revealed that the curlier the hair is, the thinner it is [17]. In contrast, in the case of mixed-race subjects, it was found that curly hair was thicker than loose wavy hair on an individual's head (Figure 3). It is thought that curly and loose wavy hairs of mixed Brazilian subjects in this study mainly represent the characteristics of Africans and Caucasians, respectively. The result is that curly hair is thicker and more elliptical than loose wavy hair (Figure 3) corresponding with reported ethnic characteristics [3,5]. Compared with the values of the cross-sectional area of the hair of Africans, however, it was found that curly hairs of the mixed Brazilian subjects are much thinner [17]. In addition, very curly hair of types VI, VII, and VIII, and the torsion of the hair stem, which is often seen in African hair, were not seen in the hair of mixed Brazilian subjects in this study. It is supposed that genetic traits involving hair shape are partly kept, and partly blended.

\section{Conclusions}

This study of the hair of mixed-race subjects reports their unique characteristics, which have never been previously observed in subjects with only one racial background:

- The hair shapes varied widely, even on a single head. The author had imagined that ethnic characteristics may be blended to exhibit a medium waviness (or curliness), so this finding was unexpected. 
- The hair surface is severely damaged near the proximal end. Regardless of whether hair is loose wavy or curly, the level of damage is similar, and far exceeds that of Asians and Caucasians. It is noteworthy that the damage does not get worse within the range of $60 \mathrm{~mm}$ from the proximal end. This damage is thought to be caused by entanglement, due to the presence of various curl phases. The heavy use of conditioning products that are common to Brazilians may protect their hair against further damage. It is expected that by extending this study over the other areas where the fusion of ethnicity is proceeding, we can acquire further findings for consumers' benefit.

Funding: This research received no external funding.

Acknowledgments: The author is grateful to Takuya Miyagawa (Kao Corp.) and Eliana Eiko Harada (Tomo Assessoria) for their helpful contributions.

Conflicts of Interest: The author declares no conflicts of interest.

\section{References}

1. Takahashi, T.; Hayashi, R.; Okamoto, M.; Inoue, S. Morphology and properties of Asian and Caucasian hair. J. Cosmet. Sci. 2006, 57, 327-338. [PubMed]

2. Takahashi, T.; Breakspear, S.; Mamada, A.; Okamoto, M.; Inoue, S. Morphology and Properties of Asian hairsChinese, Thai and Japanese Hair-. In Proceedings of the 9th ASCS Conference, Yokohama, Japan, 2-4 March 2009; pp. 244-245.

3. Franbourg, A.; Hallegot, P.; Baltenneck, F.; Toutain, C.; Leroy, F. Current research on ethnic hair. J. Am. Acad. Dermatol. 2003, 48, S115-S119. [CrossRef] [PubMed]

4. Thibaut, S.; de Becker, E.; Bernard, B.A.; Huart, M.; Fiat, F.; Baghdadli, N.; Luengo, G.S.; Leroy, F.; Angevin, P.; Kermoal, A.M.; et al. Chronological ageing of human hair keratin fibres. Int. J. Cosmet. Sci. 2010, 32, 422-434. [CrossRef] [PubMed]

5. Hayashi, S.; Okumura, T.; Ishida, A. Preliminary study on racial difference in scalp hair. In Biology and Disease of the Hair; Kobori, T., Montagna, W., Eds.; University of Tokyo Press: Tokyo, Japan, 1976; pp. 555-561.

6. Galliano, A.; Saint Olive Baque, C.; Marty, G.; Nedelec, B.; Gauchet, L.; Littaye, P.; Gu, W.; Huguet, E.; Querleux, B.; Silberzan, I.; et al. Resistance of human hair cuticle after a shaking process in wet conditions: Comparison between Chinese and Caucasian hair. Int. J. Cosmet. Sci. 2010, 32, 356-368. [CrossRef] [PubMed]

7. Baque, C.S.O.; Zhou, J.; Gu, W.; Collaudin, C.; Kravtchenko, S.; Kempf, J.Y.; Saint-Léger, D. Relationships between hair growth rate and morphological parameters of human straight hair: A same law above ethnical origins? Int. J. Cosmet. Sci. 2012, 34, 111-116. [CrossRef] [PubMed]

8. Seshadri, I.P.; Bhushan, B. Effect of ethnicity and treatments on in situ tensile response and morphological changes of human hair characterized by atomic force microscopy. Acta Mater. 2008, 56, 3585-3597. [CrossRef]

9. Ji, J.H.; Park, T.S.; Lee, H.J.; Kim, Y.D.; Pi, L.Q.; Jin, X.H.; Lee, W.S. The ethnic differences of the damage of hair and integral hair lipid after ultra violet radiation. Ann. Dermatol. 2013, 25, 54-60. [CrossRef] [PubMed]

10. Wade, M.; Tucker, I.; Cunningham, P.; Skinner, R.; Bell, F.; Lyons, T.; Patten, K.; Gonzalez, L.; Wess, T. Investigating the origins of nanostructural variations in differential ethnic hair types using $\mathrm{X}$-ray scattering techniques. Int. J. Cosmet. Sci. 2013, 35, 430-441. [CrossRef] [PubMed]

11. Marti, M.; Barba, C.; Manich, A.M.; Rubio, L.; Alonso, C.; Coderch, L. The influence of hair lipids in ethnic hair properties. Int. J. Cosmet. Sci. 2016, 38, 77-84. [CrossRef] [PubMed]

12. Lozano, I.; Saunier, J.B.; Panhard, S.; Loussouarn, G. The diversity of the human hair colour assessed by visual scales and instrumental measurements. A worldwide survey. Int. J. Cosmet. Sci. 2017, 39, 101-107. [CrossRef] [PubMed]

13. Loussouarn, G.; Garcel, A.L.; Lozano, I.; Collaudin, C.; Porter, C.; Panhard, S.; Saint-Léger, D.; Mettrie, R. Worldwide diversity of hair curliness: A new method of assessment. Int. J. Dermatol. 2007, 46, 2-6. [CrossRef] [PubMed]

14. Takahashi, T.; Mamada, A.; Breakspear, S.; Ito, T.; Tanji, N. Age-dependent changes in damage processes of hair cuticle. J. Cosmet. Dermatol. 2015, 14, 2-8. [CrossRef] [PubMed]

15. Miyagawa, T. Study of Brazilian hair care custom. Unpublished work. 
16. Fregonesi, A.; Scanavez, C.; Santos, L.; Oliveira, A.; Roesler, R.; Escudeiro, C.; Moncayo, P.; Sanctis, D.; Gesztesi, J.L. Brazilian oils and butters: The effect of different fatty acid chain composition on human hair physiochemical properties. J. Cosmet. Sci. 2009, 60, 273-280. [CrossRef] [PubMed]

17. Porter, C.E.; Dixon, F.; Khine, C.; Pistorio, B.; Bryant, H.; Mettrie, R. The behavior of hair from different countries. J. Cosmet. Sci. 2009, 60, 97-109. [CrossRef] [PubMed]

(C) 2019 by the author. Licensee MDPI, Basel, Switzerland. This article is an open access article distributed under the terms and conditions of the Creative Commons Attribution (CC BY) license (http://creativecommons.org/licenses/by/4.0/). 